\title{
BANKS AND FINTECH: IMPACT OF TECHNOLOGICAL INNOVATION ON COMPETENCES MANAGEMENT IN LATVIA
}

\author{
Andris Nātriṇ̌s \\ BA School of Business and Finance, Latvia \\ Andris Sarnovičs \\ BA School of Business and Finance, Latvia \\ Elīna Mikselsone \\ BA School of Business and Finance, Latvia
}

\begin{abstract}
Purpose: To explore information and communication technologies (ICT) impact on competences management in the financial sector in Latvia.

Methodology: Focus group discussion with leading financial sector experts in the Latvia.

Findings: There is a mismatch between academically provided competences and what is expected by the financial sector representatives within Latvia.

Originality/value: Empirical research on what kind of competences are important in the financial sector at present and in the future. Contribute to the current literature by researching on how resulting competencies from the focus group compare to the academically provided competences for potential financial sector employees. By exploring received responses to the questions from this research, it can help policymakers, financial sector and academical representatives to stay agile to the arising changes of supplied and demanded competencies in the financial sector.
\end{abstract}

Keywords: Competences Management, Financial Sector, Financial Technologies (Fintech), Latvia, information and communication technologies, ICT.

\section{Introduction}

For this research project, the financial sector refers to the classic financial sector, which consists of commercial enterprises and mixed financial holding companies of credit institutions sector, insurance sector and investment services sector, irrespective of whether these companies are located in one or more countries. In addition to the unconventional financial sector, FinTech, the financial sector covers a very diverse profile of financial services start-up companies that have emerged over the past decade as a growing segment. The operational capacity of these companies is the result of the increasing emergence of new business niches, which in turn are related to the digital ecosystem phenomenon that characterizes the ultimate customer operating conditions in the 
Nātriņ̌̌ et al., 2021. Banks and Fintech: Impact of Technological Innovation on Competences Management in Latvia

digital environment. This indicates that exploring synergies between the financial sector and ICT is essential. The financial sector's operating environment changes dynamically as a result of the digitalization process. Such changes lead to the development of new industries, the transformation of existing industries, radical changes in management processes, transformation and formation of new business models, altered relationships between customers and other stakeholders, as well as significantly affect other characteristics of the financial sector. These changes also significantly impact the availability of financial products and the scale of customer reach, new service niches, and new financial services, and financial intermediation service start-up companies are emerging, which in many cases for specific client segments even replace the previously used services and providers.

The financial sector of Latvia faces these changes and a variety of challenges: (1) the rapid emergence of technology-based start-up companies in the financial sector, and the activity of these companies substantially changes the conditions of competition in the financial sector and requires the development of new competencies for operating in the digital environment; (2) the rapid refusal to service customer transactions originating from the CIS countries using the status of a foreign registered company. Furthermore, this study is also important on a national level, because the view of the relatively large share of the financial sector in the economy as of today, as well as other aspects - including the number of employed in Latvia, which have experience in the financial sector, the share of graduates in higher education programs in social sciences disciplines, etc., provide a rational reason for research-based discussions about the financial sector as a niche in the Latvian economy while emphasizing the sustainability dimension of such a specialization.

Both global and regional changes make it necessary to raise the issue of the competencies required to address a range of issues important for the long-term competitiveness of the financial sector. For example, the global management consulting firm McKinsey describes the change in the financial intermediation sector through the bank's RoE prism, offering two scenarios. The first of these is that banks will be able to retain a significant degree of dominance in the market for traditional and also newly established financial intermediation services. The second scenario envisages that banks will "give up" their positions to new entrants, specializing in challenging digital technology adaptation to meet both traditional and unprecedented needs of financial customers. In McKinsey's view, in the first case (referred to as a "new reality" by the consulting firms) the global return on bank assets will even increase from $8.6 \%$ in 2016 to $9.3 \%$ in 2025, while in the second case ("the worst-case scenario") it will fall to 5.2\%. Appreciation of the changing situation requires noting the place of deployment of financial intermediary institutions as a factor. To characterize this, McKinsey analysts suggest analyzing the real and expected future changes in the value of financial 
intermediation service providers (international financial groups) due to the decrease in the relevance of their direct geographic presence.

According to data from the Ministry of Economics of Latvia, the investment volume in fast-growing technology companies in the Baltic States has already reached 518 million EUR by 2018. Extensive development opportunities are also one of the reasons why the "Law on Aid for Start-up Companies" was created and adopted in Latvia. Various global examples show that technology companies can create alternative offers to traditional industries. This often involves access to large data arrays based on new technologies and a more flexible internal environment and working methods that are often not feasible for traditional and experienced market players. However, the successful use of new technologies requires not only technologies themselves, but also industry and product knowledge to refer them to consumer targeted solutions and products.

The relevance and necessity of such field and topic research is largely determined by the set of practical challenges facing both financial policy creators and regulators of different levels and scales, companies from different financial services industries, and financial education product developers. Within the framework of this project, it is planned to look for research-based answers to questions that would allow policymakers, companies, and academic institutions to make rational decisions thus understanding competencies that are and will be important in the financial sector.

Based on the scientific and practical actuality paper authors have defined the research aim: to conduct a focus group of experts in Latvia financial sectors to explore ICT impact on competences management in the financial sectors Latvia. The methodology used within this research is a focus group discussion with the leading financial sector experts in the Latvia.

\section{Theoretical Aspects of Competences in the Financial Sector}

One of the main topics extensively reviewed in academic literature is a shift of contemporary companies to knowledge-intensive business models, which are rapidly growing together with the knowledge-based economy (Lu et al., 2011), where companies decrease levels of bureaucracy, simplify administrative processes, reshape the core of the business and all of this results in new competency demands (Kansal \& Sandeep, 2018).

During the past decade, competency management has come to the foreground driven by an increasing scientific interest in the topic (Wickramasinghe \& De Zoyza, 2011; Kansal \& Singhal, 2018).

The authors of this research have noted that there exist different competency definitions offered in various academic studies. Competency is extensively defined as a performance aspect for the combination of skills, knowledge, 
Nātriņ̌̌ et al., 2021. Banks and Fintech: Impact of Technological Innovation on Competences Management in Latvia

expertise, values, social and methodical abilities, ambitions and attitudes that are used by individuals for personal growth to perform specific tasks effectively in line with values and goals of the organization (Kansal \& Singhal, 2018; Colomo et al., 2013; Bohlouli et al., 2017).

Wickramasinghe and De Zoyza (2011) point out that competencies contain individual level and organizational level aspects; therefore, both levels will be discussed separately, although individual level competencies are linked to organizational level competency. The authors define organizational level competency as a set of assets, processes, routines, and a combination of competencies from multiple individuals that provide effective process performance, competitive capabilities, and sustainable advantage in comparison to other organizations. Literature sources are intermixing terms "competence" and "competency" quite often. The authors of this research specify that the term "competence" describes a performance aspect for the required set of skills so that necessary tasks may be performed effectively, but "competency" is related to the behavioural characteristic of an individual. Kansal and Singhal (2018) argue that proper competency results in incompetence. Wickramasinghe and De Zoyza (2011) define that "competence" is the reached standard of performance, but "competency" describes the behaviour and set of characteristics by which "competence" is reached. The authors clarify these terms more specifically through their plural meaning and state that "competences" describe the effective consolidated set of skills, knowledge, and abilities, while "competencies" mean effective performance behaviours.

Colomo et al., (2013) argue that competencies can be classified as generic and technical, where technical competencies can be linked directly to specific job positions, activities, functions or tasks with specific skills and knowledge. Generic competencies are not linked to any specific activity or function but helps individuals improve holistic process performance and better adapt to changes.

Wickramasinghe and De Zoyza (2011) state that individual-level competencies can be split into input and output competencies. Knowledge, attitudes, skills, and technical knowledge are considered to be inputs, but competency presentation to share results of exceeded work standards is regarded as outputs. Bohlouli et al., (2017) agree with Wickramasinghe and De Zoyza (2011) and supplement the above individual level competencies aspect by a statement that self-direction is a crucial component in the individual set of competencies, especially when an individual is facing specific challenges, previously imperceptible situations, job roles or goals. Kansal and Singhal (2018) state that competencies can be trained and measured due to their behavioural nature. The authors point out that trained and measured competencies result in ineffective job performance. 
Based on the definitions collected from literature sources, the authors of this research put forward a proposal to define individual competency and organizational level competency. Individual competency is a set of ambition, skills, knowledge, and characteristics a self-driven individual uses and can train to achieve personal effectiveness. Organizational level competence is a set of ambitions, skills, knowledge, and characteristics owned by a company through employees, which measures and predicts employee effectiveness to achieve organizational goals.

The authors of this article argue that models of competences management in technology and knowledge-intensive companies acquire their own specific and special features in the digital era, which distinguish them from previous approaches. In academic literature, such a distinction is described by comparing the traditional, qualifications-based, and workers-oriented management model. The traditional model means that recruitment, training, and development of employees takes place by focusing on positions and their tasks. Such a model is not based on the assessment and development of talents. The qualification-based model is geared toward education and qualifications. On the other hand, the worker-oriented model contributes to focusing on personal characteristics and abilities in recruiting workers, in addition to education and qualifications. This could lead to better conditions for creating a higher operational efficiency of the organization for different competencies (Baran et al., 2014).

It is challenging to use traditional human capital metric practices in today's structure, especially given the dynamics of organizations (Chrysler-Fox et al., 2014; Dewangen et al., 2014).

An important focus is to link the dimension of human capital and the investment needed to build it, transforming it into a strategic and budget planning and control KPIs (Zupančič, 2018). However, it should be recognized that the management of competences through the investment dimension requires a qualitative extension of an efficient structure of competences, which in practical terms also means the ability not to overpay for acquiring skills that are sufficiently exclusive and costly and which, under certain conditions, can lead to higher added value, but in another situation, can also not to be used.

The competence management model must be based on the objectives, values, strategic and tactical tasks of the organization, the culture of the organization and the expected style of work, to achieve the degree of organization competence (such as consolidated performance at the level of the organization, as determined by the knowledge, skills, talents, attitudes of the individuals involved in it), which presupposes the organization to be able implement their strategies and tasks. In the context of business challenges, this means ensuring competitiveness and sustainability (Brits et al., 2014; Baran et al., 2014). 
Nātriņ̌̌ et al., 2021. Banks and Fintech: Impact of Technological Innovation on Competences Management in Latvia

\section{Research Methodology}

Main research method for data collection: focus group discussion. Data analysis method: a thematic analysis. Focus group plan was divided into 3 main parts:

Part 1 - Introduction:

1) purpose of study and appointment;

2) accomplishments in the field (conferences, articles);

3) introduction of participants in the discussion.

Part 2 - World Cafe (15 min):

1) Table 1 "Banks"/ Table 2 "Fintech": What competencies are currently relevant in the financial sector? What could they possibly be in the future?

2) Table 3 "Universities (Academical)": What competencies do academic institutions offer to future professionals in the financial sector? What competencies does it intend to offer?

The Focus group was divided into three main parts: banks, fintech, and universities. Main criteria of moderators: academically involved in BA School of Business and Finance internal grant research about financial competences. Criteria for focus group representatives at least 5 years of practical or academic experience in the field.

Focus group (World café) participants and grouping:

World café (Bank representatives - table I)

Moderator: Andris Nātriṇš, BA School of Business and Finance

Representatives:

- $\quad$ CDO, Swedbank Latvia (acting in Latvia, Lithuania, Estonia, Sweden)

- $\quad$ Data base and integration team lead, SEB Bank (Latvia)

- $\quad$ CEO, Luminor Group, Asset Management unity (Latvia)

- $\quad$ Head of Risk Center, SEB Banka (Latvia)

World café (FinTech representative - table II)

Moderator: Didzis Rūtitis, BA School of Business and Finance

Representatives:

- $\quad$ IT lead, Twino (Latvia, Poland, Denmark etc.)

- $\quad$ CEO, Monea (Latvia)

- Head of Product, Mintos (Latvia and 33 countries)

- Business Analysis Manager, 4 Finance (Latvia, Riga Technical university)

World café (University (Academical) representatives - table III)

Moderator: Elina Mikelsone, BA School of Business and Finance

Representatives:

- Rector, BA School of Business and Finance 
- $\quad$ Professor (Faculty, IT department), Riga Technical university

- Study programme director, BA School of Business and Finance

- $\quad$ Researcher (postdoctoral), BA School of Business and Finance

Part 3 - Classic discussion: the moderator identified the message and outlined the main conclusion from the previous researches, then detailed discussion. The entire discussions audio is recorded. Additionally, there are developed discussion question pages where representatives of the focus group can make the main notes about their opinion about the questions.

\section{Findings}

World Cafe Table I. (Banking perspective) - in terms of competencies demand, banks are traditional financial institutions subject to stricter regulation. In banking, risk, customer service/front-office, product and service development, back-office and ICT support functions can be distinguished. At present, reaching a customer has become complicated, you have to adapt to the way people "live" in the digital environment. Relevant competencies must be acquired. The development of a product or service is currently taking place in micro-service groups, where there are professionals with different competencies that are needed to create these products. Back office and ICT common competencies in banks and fintech: greater importance for general competencies such as communication skills (empathy) and design thinking. These competencies are required for all positions in the bank. ICT skills and knowledge are important and required in more or less all positions, the degree or level of competence on average - 3.5 out of 5 points. In risk positions and product-service development positions - 4 out of 5 points. For ICT, of course, the highest level of competence is required. ICT requires algorithmic thinking, mathematics, statistics (especially in risk management). Key Competencies - data analysis, with the growing role of big data analysis competencies. Back-office - automation and machine learning solutions are topical. The specific characteristics of the bank - a lot of conditions, requirements are different and less flexible, which is an additional burden. Banks have a complex system architecture and requirements to adapt their processes more to it.

World Café Table II. (Fintech perspective) - in terms of the impact of technology on competency management in the financial sector, the main focus is on the product or a solution, its development and promotion without a sufficient set of competencies. At the management level - equal understanding of all steps in technological development. It relates not only to the ability to work with ICT tools or platforms but also to the ability to estimate time and money, as well as the ability to evaluate the technology as a whole and its benefits. For example, an understanding of available marketing solutions is important in the field of digital 
Nātriņ̌̌ et al., 2021. Banks and Fintech: Impact of Technological Innovation on Competences Management in Latvia

marketing. If skills are mentioned, they must provide the ability to define the requirements for the technological solutions for ICT departments or ICT-led projects. There must be mutual interdisciplinary communication between departments. In today's fintech companies, business analytics, as well as project management competencies, are critical. Topical questions about the current data protection regulations (GDPR), including anti - money laundering (AML).

World Café Table III. (Academical perspective) - in terms of the offer of competencies, the offer of higher education for modern and future-oriented educational products that may be in demand in the FSP sector:

1. Application design and smart logistics in all management programs.

2. Knowledge of the most current ICT trends and opportunities in both management and financial study programs.

3. Web application programming, ICT security, financial flow, security analysis, virtual team management, technology development monitoring and planning - in ICT programs that prepare specialists for Financial sector companies.

On the inherent changes in the Financial sector: traditional financial institutions and fintech.

A characteristic feature of the Financial sector: prioritization of user experience - broad knowledge of the customer's behavior and perception is an important competence in implementing processes in the key business functions of companies, namely, product development, sales and risk management. The topicality of the banking sector is the changing of the banking business model from closed to Open Banking. In terms of the customer service: banks can serve not only own products but also products of partners or even competitors. As a result, the bank's structure and process management are changing and it is important to understand what a bank is and what is infrastructure. Also, what is part of the products and what is part of the sale or distribution. In the past, it could all be easily counted as one cumulative result. In this case we have to calculate each part separately because each part can be replaced by another component.

ICT platforms of companies in the Financial sector, which were built in a different reality with risk assessment, building partnerships with product integration rather than building the products themselves. Speed and meet the customer needs is a priority in the Financial sector. Security is important, but just as important is what the digital environment offers - speed and convenience. Priorities change directly from the customer's perspective. Nowadays, financial services can be offered by a technology company, which makes the service easier and more convenient.

The biggest change in the financial sector is that services are becoming more affordable and accessible. Customers are being approached more precisely. The driving force behind it - cloud services. Financial literacy is higher for the 
population because there are different banks and the customer is forced to evaluate which offerings and services fit them the best. Technologies will use this opportunity to serve customers who historically have had insufficient access to financial services (under-served).

The banking industry does not provide sufficiently good services, so new ideas have emerged. Existing players are forced to think differently than before. Some see it as an opportunity, others as a threat. Development requires new types of settlement or new business models and results in a product that is followed by regulation.

All processes that are standardizable are subject to digitization. Banking services are standardized and replicable. The technology is expected to be used in both external and internal financial corporate processes, including regulatory enforcement.

\section{About Business Models, Their Classification}

Fintech companies have introduced new features in their business modelling approaches in the Financial sector. The segments of the business model have become narrower, the basic model is based on one service and it is expanded in various ways and also supplemented with new services. For example, Financial sector participants can start a business with payment cards and accounts, but then find their niche in the market with modified services and additional product offerings.

P2P Investment (Twino, Mintos) is a relatively narrow niche that has recently emerged. The goal - to segment one business model, on one side an investor on the other side a borrower. The model aims to bring them together with the help of a platform. The Financial sector in Latvia is interesting, creating good preconditions to try other services, such as online lending, without P2P investment (a platform to create an opportunity for one part of customers to invest in targeted investments for another group of platform clients - borrowers).

When creating a business model, each has to find what they are best at, and what are the best elements to start with, given that the others will fail. Once your niche is found, it needs to be scaled. Then you need to find partners. When looking ahead, it looks like there will be no single prominent leader in the Financial sector, but more of coexistence for both global and regional platforms. The trend at the moment is that from a customers' perspective, customers will not look for and/or use a single product separately (as is the case when people turn to different platforms for different solutions). When using Google's platform to travel, the user is promptly offered booking.com and insurance as well as a bank. The range of core products for banks is expected to be relatively small. Basic business models for banks value vs valuation business model, how to consistently offer 
Nātriņ̌̌ et al., 2021. Banks and Fintech: Impact of Technological Innovation on Competences Management in Latvia

value and create loyalty and a reliable model so that there are no surprises in the future.

If in the banking sector, we will live in categories of resident and nonresident banks for some time to come, then the boundaries will start to disappear, because the customer can use the services in non-banks. Fintech platforms, registered in Latvia, operating globally. When assessing the differences in business models in the Financial sector, it can be concluded that the banks are focused on the customer, but fintech - on the product.

The focus group revealed a possible difference in the wording of the situation regarding the typical features of business models of banks and fintech companies. In response to the question whether a company can build a team with a strong core, or whether a company is stronger if it can attract people from outside in the form of projects, fintech companies have an approach in practice: with rapid growth, one team will not be able to use existing technology in which they are strong because there will be other needs. Therefore, attract new teams with new solutions. After that, team interaction is important.

\section{Technologies for Implementation of Business Models and Goals in the Financial Sector}

The most common approach of Latvian fintech companies to the selection and use of technologies for product development - it is best if the technological solutions have to be created by themselves to be able to tailor it to their needs. Once a technology has been purchased, it cannot be changed. Therefore, it is more characteristic of the Fintech industry that the company develops its systems so that they can later be applied to the appropriate product type. A deciding factor is a person who knows what and how to work with any type of technology.

P2P investment companies use, for example, JAVA Technology (Twino) to create their applications. "Improve it" with available technologies, but the basic or core platform is formed by the company itself. Everything is built on an internally created platform, including using other services and solutions to save time. There must be a core platform capable of communicating with all other micro-services. The basic module of a P2P is the Credit scoring module. Calculation in which - the more complete this module is, the more it is possible to apply it to the customers. The platform must be scalable and adaptable as needed, due to the changing needs and the demand. 


\section{Banks in the Financial Sector}

The challenge for banks in the current situation is how to transform existing monolithic ICT systems to be compatible with possible extensions that can be developed in an open-source architecture and can be better adapted to ensure cooperation, including through the micro-service development architecture. In the future, banks will not be drivers of innovation, as they will have to take too many innovation risks. The topicality of open banking is related to this.

In Banks, new approaches require that every employee in the company fully knows the product by heart, not only in their department but also be able to generate new ideas for innovation and demand. Employee responsibility involves engaging in banking processes, as well as the ability to break down processes into smaller steps to create a quality product or service.

Fintech companies create their applications that run online and can be widely used. Technologies and platforms will be successful and support the business model if they are designed to improve and adapt quality in the future, as each company has its policy and needs to be taken into account. Platforms must be able to work with the company's microservices.

\section{Technological Expertise in Financial Sector Companies}

For Fintech industry companies: Given that they focus on self-developed solutions and adaptations, it is important to develop in-house appropriate and higher-level technological competencies that directly and effectively serve business development tasks, following the chosen strategy and business model.

\section{Business Models, Competences and Competitiveness in the Financial Sector}

The focus group participants emphasized the specificities arising from how technologies are disseminated, enabled and developed. How it manifests itself in the demand, application and also dynamics of competencies. In addition, both in terms of the overall set of competencies and in the form of aggregated organizational competencies, which create the preconditions for certain capabilities of a particular company to achieve a certain level of performance.

In the financial services sector, there is currently a tendency for technological innovations to create new competencies, replacing the old ones, which means that there is a greater focus on technology knowledge than on business analytics. At the same time, it cannot be said that skills and knowledge of other processes, such as those related to risk management, the financial market and the like, are not needed, as the nature of banking and financial services remains the same. 
Nātriņ̌̌ et al., 2021. Banks and Fintech: Impact of Technological Innovation on Competences Management in Latvia

When it comes to ICT development, we also need to think about potential consumers, because in the 21st century, everything is rapidly being modified and integrated. As a result, people are sometimes unable to accept and understand innovative products. Consequently, the product must be designed in such a way that technological innovations do not place an additional burden on their uptake.

At present, companies in the financial sector expect more from employees than was previously required. The knowledge gained in higher education institutions is not sufficient today. A significant shortcoming - study programs are not based on technologies and their acquisition.

It is important for Fintech companies that a person can apply all the acquired theoretical knowledge in practice and can become a project manager or promoter in their field. However, currently, no such specialization can be found in higher education institutions. Project management involves understanding how small details are created in each industry. It is very difficult to create an educational program using abstract concepts.

How to develop competence in the study process:

- In the study process it is necessary to look at several products, both in the development stages and in practice, and analyse them as examples. Only in this way it is possible to understand what is being used more.

- Concerning project management, it is necessary to develop product management knowledge, which in turn includes the ability to weigh what it consists of. Only then can we talk about ICT skills.

On the readiness of ICT students to easily integrate into professional processes:

- $\quad$ there is a lack of understanding of the development process in project processes, as they typically take place in companies in the financial sector. More knowledge is needed in several areas to make project implementation more effective.

- $\quad$ Fintech companies expect that ICT graduates will not only be excellent programmers but will have additional knowledge related to other competencies.

- $\quad$ One of the main things that change with the growth of fintech - the new approach means that every employee in the company knows their product by heart, without sorting departments. This is important for quickly building micro-service project teams. It is important to know each other in the team and everyone knows the product, so that as a team together you can lead the whole project equally.

- At the moment, an important competence for Financial sector companies is understanding what systems need to be business-friendly. 
It is important to be able to solve problems more quickly if they arise, as this affects the speed at which a solution can be found.

- Added value for an ICT specialist - to know business processes, the ability to get into a team as soon as possible and be a team player rather than an executor.

- Greater added value if students had more flexibility and an understanding of the basics (universal soldiers).

- The golden middle way in the content of ICT study programs, so as not to have too many deep details, such as not to teach network architecture.

- $\quad$ "The programmer emerging from higher education is not ready to work and is prepared to concentrate in a specific area." (ICT specialists' readiness to fully integrate formal education into the working environment). A lot of resources should be invested on the part of the company to do this. In other areas, such as project management, business analytics, the situation is better.

\section{Future Financial Sector Competencies Needs}

- Demand for competencies from the perspective of leading experts in the financial sector: In the Financial sector, project management skills are expected to be the most important in the future.

- $\quad$ Project management approaches such as agile must be well mastered. In building ICT competencies, it is important to focus less on specific programming languages and focus more on the process, design thinking.

- Understanding business processes will be just as important for IT professionals as technological knowledge; programming languages can be learned, and their range also changes.

- An understanding of the system architecture and its design is essential for IT specialists. The regulatory area and related competencies are also important.

The technology companies can create alternative offers to traditional industries. This often involves access to large data arrays based on new technologies and a more flexible internal environment and working methods that are often not feasible for traditional and experienced market players. The successful use of new technologies requires not only technologies themselves, but also industry and product knowledge to refer them to consumer targeted solutions and products.

The labour market expects the same person's knowledge related to ICT, financial analytics, human psychology (understanding of behavioural patterns), 
Nātriņ̌̌ et al., 2021. Banks and Fintech: Impact of Technological Innovation on Competences Management in Latvia

etc. spheres. It is also important for a person to be able to work together in a team. It is important to prepare future employees of financial sector companies, particularly in the fintech industries, to realize certain roles that are useful in the development of technology-based products within micro-services architecture. Employees with deep knowledge of IT must also have business awareness and knowledge of financial products, but if their basic knowledge is business-related, there must be higher than mid-level IT knowledge and understanding of the ICT development dimension. All teams must have good collaborative capabilities and skills to operate in the agile development structure, implementing the product or process development and maintenance.

A characteristic feature of the Financial sector: prioritization of user experience. Broad knowledge of the customer's behaviour and perception is an important competence in implementing processes in the key business functions of companies (product development, sales, risk management etc.). The most significant changes are in the banking business model, which include not only products of this bank but also partners (other financial institutions). As a result, the bank's structure, products, process, HR management are changing.

There is a mismatch between academically provided competences and what is expected by the financial sector representatives within the Latvia.

\section{Conclusions}

The experts' views in the discussion make it possible to extend the insight into technology usage considerations in the banking industry and fintech counterparts, sometimes opposing the lessons argued in academic publications. It is also the task of qualitative study methods (expert focus groups). This, in the authors' view, is important in choosing future research directions.

The authors agree with Gomber et al., (2018), that financial-services sector companies, including banks, have traditionally been more representative of the intensity of technology deployment than other service sectors. Similarly, the authors agree with Li et al., (2017), Shulte et al., (2017), Gomber et al., (2018), the financial sector is being challenged by firms that combine finance and technology that create customer-oriented innovation, while traditional companies are experiencing the process and changing the business model. However, the expert opinion points out that there is a clear understanding of how the overall situation in the financial services sector changes, how value chains change in terms of technology, how banks can adapt to these changes, like companies from other financial industries. According to the authors, the experts' views suggest that owning one of the industries in itself does not mean better or worse positions. At the moment, we can make sure that banks are able to successfully integrate elements specific to digital innovation ecosystems, to incorporate into change by 
losing exclusivity in traditional positions, but by gaining natural benefits, including based on the experience of smart skills management, within the new framework.

The investigation of competence management models is an up-to-date topic in both academic and practical contexts. This applies to the greatest extent to the competences management of financial sector undertakings, particularly take into account, that competence and competence management has not been sufficiently studied concerning this sector. The relevance and necessity of such field and topic research is largely determined by the set of practical challenges facing both financial policy creators and regulators of different levels and scales, companies from different financial services industries, and academical institutions.

\section{Acknowledgements}

Research developed with the support by BA School Business and Finance Internal Grant Program 2018.

\section{References}

Baran, M., \& Klos, M. (2014). Competency Models and The Generational Diversity Of A Company Workforce. Economics \& Sociology, 7(2), 209-217.

Bohlouli, M., Mittasb, N., Kakarontzas, G., Theodosios, T., Lefteris, A., \& Madjid, F. (2017). Competence assessment as an expert system for human resource management: A mathematical approach. Expert Systems with Applications, 70, 83-102.

Brits, D., \& Veldsman, T. (2014). A global central banker competency model. South African Journal of Human Resource Management, 12(1), 1-14.

Chrysler-Fox, P., \& Roodt, G. (2014). Changing domains in human capital measurement. South African Journal of Human Resource Management, 12(1), 1-12.

Colomo - Palacios, R., Casado - Lumbreras, C., Soto - Acosta, P., Garcia - Penalvo, F., \& Tovar - Caro, E. (2013). Competence gaps in software personnel: A multi-organizational study. Computers in Human Behavior, 29(2), 456-461.

Dewangen, V., \& Godse, M. (2014). Towards a holistic enterprise innovation performance measurement system. Technovation, 34(9), 536-545.

Gomber, P., Kauffman, R. J., Parker, C., \& Weber, B. W. (2018). On the Fintech Revolution: Interpreting the Forces of Innovation, Disruption, and Transformation in Financial Services. Journal of Management Information Systems, 35(1), 220-265.

Kansal, J., \& Singhal, S. (2018). Development of a competency model for enhancing the organisational effectiveness in a knowledge-based organisation. International Journal of Indian Culture and Business Management, 16(3), 287-301.

Li, Y., Spigt, R., \& Swinkels, R. (2017). The impact of FinTech start-ups on incumbent retail banks' share prices. Financial Innovation, 3(1), 1-16.

Lu, H., Lo, C., \& Lin, P. (2011). Competence analysis of IT professionals involved in business services - Using a qualitative method. In: 2011 24th IEEE-CS Conference on Software Engineering Education and Training (CSEE\&T), Honolulu, HI, 61-70, 
Nātriņ̌̌ et al., 2021. Banks and Fintech: Impact of Technological Innovation on Competences Management in Latvia

Schulte, P., \& Liu, G. (2018). FinTech Is Merging with IoT and AI to Challenge Banks: How Entrenched Interests Can Prepare. Journal of Alternative Investments, 20(3), 41-57.

Zupančič, M. (2018). Employees: Invisible Added Value of a Company. Nase Gospodarstvo, 64(2), 52-60.

Wickramasinghe, V., \& De Zoyza, N. (2011). Managerial competency requirements that enhance organisational competences: a study of a Sri Lankan telecom organisation. The International Journal of Human Resource Management, 22(14), 2981-3000. 